\title{
Building a combined targeted selective treatment scheme against gastrointestinal nematodes in tropical goats
}

\author{
J.F.J. Torres-Acosta ${ }^{\mathrm{a}, *}$, M. Pérez-Cruz ${ }^{\text {a }}$, H.L. Canul-Ku ${ }^{\mathrm{a}}$, N. Soto-Barrientos ${ }^{\mathrm{b}}$, \\ R. Cámara-Sarmiento ${ }^{a}$, A.J. Aguilar-Caballero ${ }^{a}$, I. Lozano-Argáes ${ }^{a}$, C. Le-Bigot ${ }^{c}$, \\ H. Hoste ${ }^{\mathrm{c}, \mathrm{d}}$ \\ a Campus de Ciencias Biológicas y Agropecuarias, FMVZ, Universidad Autónoma de Yucatán, Km 15.5 Carretera Mérida-Xmatkuil, \\ Merida, Yucatan, Mexico \\ b Universidad Nacional, Campus Presbítero Benjamin Núñez, Lagunilla, Herédia, Costa Rica \\ c UMR 1225 INRA/DGER IHAP, ENVT, 23 Chemin des Capelles, F31076 Toulouse, France \\ ' Université de Toulouse, ENVT, UMR 1225, 31076 Toulouse, France
}

\section{A R T I C L E I N F O}

\section{Article history:}

Available online $\mathrm{xxx}$

\section{Keywords:}

Targeted selective treatment

Anthelmintic

FAMACHAC

Body condition score

Eggs per gram of feces

Gastrointestinal nematodes

Goats

\begin{abstract}
A B S T R A C T
The design and validation of a combined targeted selective treatment (C-TST) scheme to control gastrointestinal nematodes (GIN) of goats under tropical conditions is described. A survey performed on 1585 goats (older than 4 months) from 103 smallholder subsistence farms from tropical México (Yucatán), showed the classical over-dispersion distribution of the GIN fecal egg excretions (FEC) indicating that most goats had a low excretion of eggs and only a few had high FEC. A second stage of the survey (20 farms) tested the association between FAMACHAC and packed cell volume (PCV) $(n=638)$ as well as FAMACHAC) and FEC ( $n=627)$. The survey showed that FAMACHA@ was a good tool to identify anemic animals but no association was found with their FEC. As a result, we proposed to combine FAMACHAC with body condition score (BCS) to identify adult animals at risk of high GIN infections. The FEC was used to identify goats needing anthelmintic (AH) treatment. The C-TST scheme was surveyed in a goat farm (mean 138 adult goats/year) in Yucatán for 6 years (8292 events recorded). In that period, the mean number of goats left without AH treatment was $57.4 \%$. Meanwhile, nearly $30 \%$ of the goats needed only one treatment per year. Less than $15 \%$ of the goats required 2 or more treatments per year. Besides, the AH doses were distributed amongst small number of animals every month throughout the year. Thus, under the browsing conditions of Yucatán, México, the combination of BCS and FAMACHAC can be used as a screening procedure to identify animals at risk of severe GIN infections and the FEC help to reduce the number of goats treated per year with no apparent negative consequences on the goats.
\end{abstract}

(c) 2014 Elsevier B.V. All rights reserved.

\section{Introduction}

Targeted selective treatment (TST) is a general approach aiming at reducing the frequency of anthelmintic (AH)

\footnotetext{
* Corresponding author. Tel.: +52 9999423200; fax: +52 9999423205

E-mail addresses: tacosta@uady.mx, jfj.torresacosta@gmail.com
} (J.F.J. Torres-Acosta). treatments against gastrointestinal nematodes (GIN). The TST schemes represent a change in the way conventional AH drugs are used. Rather than treating all the animals in a group or herd, the TST aims at identifying only those highly infected animals that require an $\mathrm{AH}$ treatment, in order to prevent negative consequences on health, welfare or production, while all other animals remain without AH treatment (Van Wyk et al., 2006; Kenyon et al., 2009). The TST schemes have two main interests:

0921-4488/\$ - see front matter @ 2014 Elsevier B.V. All rights reserved.

http://dx.doi.org/10.1016/j.smallrumres.2014.01.009 
(a) maintaining refugia of susceptible parasite populations within a farm (herd) and (b) reducing the costs of $\mathrm{AH}$ treatments by reducing the use of drugs. The main limitation of any TST scheme remains to be the difficulty of identifying those animals that are not coping with worm challenge. For nearly a decade, only FAMACHA@ score and body condition score (BCS) have been regarded as being of practical value or having potential for repeatedly examining herds and identifying individuals for AH treatment (Van Wyk and Bath, 2002). However, both methodologies have limitations when applied to adult goats even under conditions where Haemonchus contortus is abundant: (i) the sensitivity of FAMACHAC scores 4, 5 to detect anemia in goats is low (23-31\%; Vatta et al., 2002a), (ii) anemia can be caused by many factors (Van Wyk and Bath, 2002), (iii) BCS is also influenced by several management and health aspects other than GIN infections (Vatta et al., 2002b). It has been suggested that the combination of FAMACHAC and $\mathrm{BCS}$, which can be applied simultaneously to a given flock, may achieve the full potential of clinical evaluation for haematophagous and non-haematophagous GIN infections (Van Wyk and Bath, 2002). We propose to use FAMACHAC and BCS to find adult goats at risk of severe GIN infections. Rather than treating animals according to those indicators, we propose to use FEC as a correction factor leading to treat anemic/emaciated goats that have a certain threshold of worm eggs. Such combination of techniques is described here as combined TST (C-TST). However, before any TST scheme is suggested, the distribution of FEC must be investigated in the goat population in the area of interest (Hoste et al., 2001). Also, FAMACHA@ must be validated before it can be used for goats in a given region (Kaplan et al., 2004; Ejlertsen et al., 2006; Mahieu et al., 2007; Scheuerle et al., 2010). The first objective was to describe the distribution of nematode egg counts in 1500 browsing goats from 103 smallholder herds and its implications for helminth control. The second objective was to evaluate FAMACHA® as a tool to identify anemic or parasitized goats in 638 animals from 20 smallholder flocks. The third objective was to determine the number of animals requiring $\mathrm{AH}$ treatment per year in a goat farm using the C-TST based on FAMACHAC, BCS and FEC measurements.

\section{Materials and methods}

\subsection{Distribution of nematode fecal eggs output in naturally infected goats}

A survey was performed in Yucatán, México $\left(20^{\circ} 52^{\prime}-19^{\circ} 30^{\prime} \mathrm{N}\right.$ and $90^{\circ} 00^{\prime}-88^{\circ} 50^{\prime} \mathrm{W}$ ) during the wet season (from July to September). The climate of the area is hot and humid with summer rainfalls. The total rainfall recorded in the study area during the survey was $\sim 530 \mathrm{~mm}$. The maximum ambient temperature varied from $39^{\circ} \mathrm{C}$ in June to $36^{\circ} \mathrm{C}$ in September and minimum temperature between $25^{\circ} \mathrm{C}$ in June and $20^{\circ} \mathrm{C}$ in September. The vegetation of Yucatán is a tropical forest with mainly deciduous vegetation to the north and perennial vegetation to the south (Flores-Guido and Espejel-Carvajal, 1994). All the herds belonged to subsistence farmers using native vegetation as the main source of nutrients for their animals. Animals browsed during the day ( $4-8 \mathrm{~h}$ per day) and were kept indoors during the afternoon and night, when supplementary feeding was provided in most cases. The goats were mainly Criollo with scarce influence of Nubian, Alpine or Saanen breeds and were kept mainly for their milk and the kids.

This survey examined the GIN fecal egg count (FEC) of all the goats older than 4 months of age from 103 smallholder flocks ( $n=1500$ goats).
Goats of the different farms were grouped by age according to observations of their front teeth: Group 1 (older than four months but younger than 1 year), Group 2 (older than 1 but younger than 2 years), Group 3 (older than 2 but younger than 3 years), Group 4 (older than 3 but younger than 4 years), and Group 5 (older than 4 years). The farmers reported that animals were not de-wormed at least in the three months before the fecal samples were taken in their respective herd.

\subsection{Evaluation of FAMACHA® in goats from tropical México (Yucatán)}

A total of 638 goats (older than 4 months of age) from 20 goat flocks surveyed were also used to evaluate the association between the FAMACHAC scores (Van Wyk and Bath, 2002), the FEC and the PCV. These three variables were determined in these goats as described below.

\subsection{Sample collection and processing in the surveys}

Blood samples were obtained from the jugular vein of each animal using needles and EDTA test tubes for each animal. Individual fecal samples were obtained from all the goats. Samples were maintained in refrigeration before processing. Animals were examined to determine their FAMACHAC score as suggested by Bath et al. (2001). The same two trained persons scored all the animals. The blood samples were processed between 2 and $4 \mathrm{~h}$ after collection using the micro-hematocrit technique. The feces were processed individually by using a modified McMaster method with an average detection level of 50 eggs per gram (EPG) of feces (Rodríguez-Vivas and Cob-Galera, 2005). The feces were used to produce bulk fecal cultures for most herds and were kept in an incubator at $27^{\circ} \mathrm{C}$ for five days. On day 6 the infective larvae were harvested and were also identified ( $\sim 50$ larvae per coproculture) using the keys of identification for ruminant nematodes (MAFF, 1986; Bowman and Lynn, 1999). In total the survey included 81 coprocultures from the different flocks.

\subsection{Implementing the C-TST combining FAMACHAC, body condition score and FEC}

The C-TST scheme was tested at the FMVZ-UADY goat farm in Mérida, Yucatán, México $\left(20^{\circ} 52^{\prime} \mathrm{N}\right.$ and $\left.89^{\circ} 37^{\prime} \mathrm{W}\right)$, from 2005 to 2010 . The farm had an average of 138 adult female Criollo goats per year, browsing in $\sim 20$ ha of nearby low deciduous tropical forest. Goats browsed daily during the morning and were kept indoors overnight where they received their daily supplement ( $\sim 200 \mathrm{~g} /$ animal/day; 74:26 sorghum meal:soybean meal). Parturition intervals of the female goats' were between 8 and 9 months and the average litter size was 1.7 kids with an average weight of $2.1 \mathrm{~kg}$ per kid. Milk was used mainly to feed growing kids in the flock.

Every 30 days, all the adult female goats were examined to determine their FAMACHAC score (as previously described) and their BCS with the methodology for tropical goats (Honhold et al., 1989). If individual FAMACHA@ and/or BCS crossed below a certain threshold (see Fig. 1) a fecal sample was obtained directly from the rectum of the animal. Fecal samples were processed immediately after collection to determine the EPG as described above. On the year 2005, the threshold to decide AH treatment was $500 \mathrm{EPG}$. After that year, the threshold used to decide AH treatment was $750 \mathrm{EPG}$. Animals needing AH treatments were injected with levamisole ( $12 \mathrm{mg} / \mathrm{kg}$ subcutaneous route). All the other animals in the herd remained untreated with AH. The FAMACHAC and BCS score were determined by the same two persons during 2005 and, after one year, one of the trained staff did all the FAMACHA@ and BCS scoring/recording. The staff recorded the following monthly events: individual identifications of animals, their BCS and FAMACHA@ scores. Animals that were sampled (feces) were also recorded together with their McMaster results. Data was stored in a data-base using Microsoft Excel 2003 and 2007.

\subsection{Data processing and statistical analyses}

\subsubsection{Distribution of nematode fecal eggs output in naturally infected goats}

Means, variance, minimum and maximum values were calculated for the EPG and PCV data of the total number of surveyed goats and also for each age group (1, 2, 3, 4 and 5) using the PROC Univariate of SAS (Cody and Smith, 1991). The program also calculated the EPG skewness in order to compare the similarity of the distribution with the normal distribution model. The EPG were transformed $(\log 10 x+1)$ before being used in the calculations (Hoste et al., 2001, 2002). The prevalence of surveyed goats 


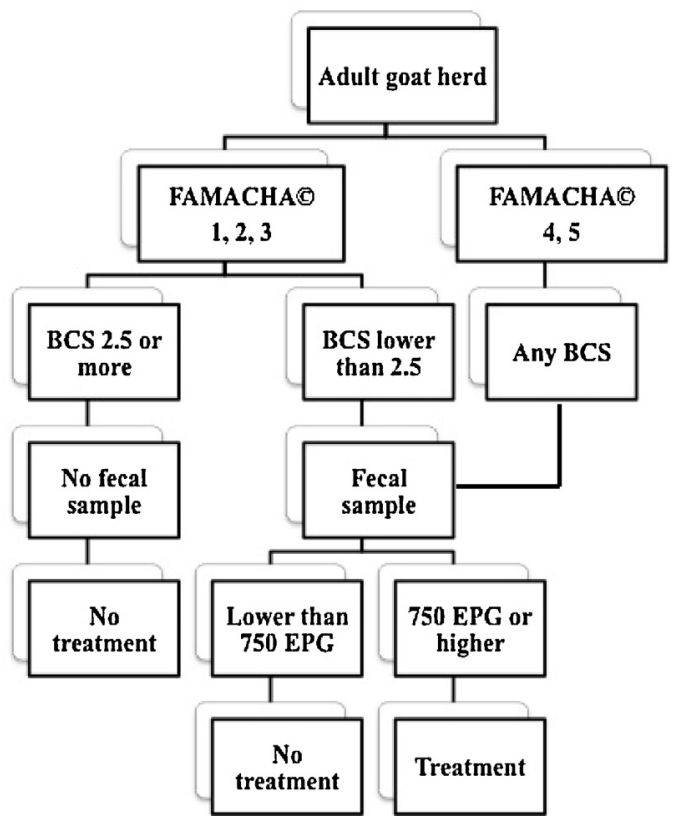

Fig. 1. Decision tree in the combined targeted selective treatment (CTST) scheme for goats with the criteria used for every step to determine when an animal was treated with anthelmintic drug. (BCS = Body condition score; EPG = Eggs per gram of feces).

with GIN nematode eggs in their feces was calculated for the total number of goats and also for each age group using the formula:

Prevalence $=\frac{\text { number of goats positive to EPG }}{\text { total number of goats in the respective group }} \times 100$

\subsubsection{Evaluation of FAMACHA® in goats of tropical México (Yucatán)}

The mean PCV values in the different FAMACHA@ scores were compared using the GLM procedure of SAS (Cody and Smith, 1991). Post hoc comparisons between PCV means of different scores were performed using the Tukey test. Separate non-parametric Spearman rank correlation analyses were performed between the PCV and FAMACHAC scores, the FEC and FAMACHAC scores and the PCV and the FEC data using the CORR procedure of SAS (Cody and Smith, 1991). Lastly, the sensitivity $=[100 \times$ true positives/(true positives + false negatives $)]$, specificity $=[100 \times$ true negatives $/($ true negatives + false positives $)]$, negative predictive value (NPV) and positive predictive value (PPV) were also calculated with confidence levels of 95\% using Win Episope 2.0 (Thrusfield et al., 2001). The values were obtained using two cut-off points: PCV of $21 \%$ and PCV of $22 \%$. The latter were chosen as the anemia threshold found in previous studies with Criollo goats from Yucatán (Torres-Acosta, 1999).

\subsubsection{Implementing the C-TST combining FAMACHAC, body condition} score and FEC

The following data were determined for every year of the C-TST: (a) average number of goats in the goat farm, (b) total number of events (all the goats checked by the staff during the year), (c) total number of events showing FAMACHAC 4, 5, (d) total number of events with a fecal sample, (e) total number of events with no fecal sample, (f) total number of events treated with $\mathrm{AH}, \mathrm{g}$ ) total number of events that were not treated with $\mathrm{AH}$, and (h) total number of events with FAMACHA@ 4, 5 that received $\mathrm{AH}$ treatment.

The number of AH treatment events per animal per year was used to calculate treatment frequency of the goats as a proportion (\%) of animals treated 0 time, 1, 2, 3, 4 or more times per year. Treatment frequencies were determined in the mean number of goats in a given year (obtained by adding the number of adult goats in each month and dividing the result by 12). The number of treatment events recorded during the dry seasons (December-May) was compared with that of the wet seasons (June-November) by calculating the odds ratio with Win Episcope 2.0
(Thrusfield et al., 2001). This was performed first using the data of year 2005 (threshold of 500 EPG) and subsequently with data from other years (2006-2010).

For this survey each goat contributed with several data per year (events). In spite of that, the individual data in a given month was considered independent to other data of the same animal in another month. The latter is supported by the fact that every goat went through several random events that could have changed their level of FAMACHA@, BCS and EPG in each month in an independent manner. Such random events included: stage of reproductive activity (mating, gestation, parturition, different litter sizes and number of lactation), changes in climatic conditions through the year (dry season or wet season, hot or cool temperatures, tropical storms and hurricanes), daily access to naturally infected pastures, daily access to tannin rich fodder, health problems (i.e., hoof and tooth problems), amongst others.

Due to the previously explained inherent nature of the events, data from all the events were used to determine the sensitivity, specificity, PPV and NPV of FAMACHA@ scores 4, 5 to detect goats with nematode egg outputs of at least 500 EPG (year 2005) using Win Episcope 2.0 (confidence level 95\%) (Thrusfield et al., 2001). The same was performed when the threshold was 750 EPG (years 2006-2010). Finally, the concordance in the number of animals found positive to 500 or 750 EPG between FAMACHAC 4, 5 and the C-TST was evaluated using the Youden J test of Win Episcope 2.0 (Thrusfield et al., 2001).

\section{Results}

\subsection{Distribution of nematode fecal egg output in naturally infected goats}

More than $90 \%$ of the surveyed goats in the 103 flocks excreted GIN eggs (Table 1). The prevalence of EPG was the highest in age Group 3 and the lowest in age Group 1. The coefficients of skewness showed that the frequency of EPG distributions was positively skewed in all age groups (above 2.46), indicating over-dispersion of EPG. Thus, most animals excreted low quantities of EPG, while very few animals shed high FEC counts. A total of 1749 L3 larvae were identified from all the coprocultures. The genera identified were Haemonchus (59.4\%), Trichostrongylus (34.2\%) and Oesophagostmum (6.5\%).

\subsection{Evaluation of FAMACHAC in goats of tropical México (Yucatán)}

The PCV value (mean \pm SEM) of the different FAMACHAC scores found in the surveyed goats were $32.2 \pm 0.75$ (score $1, n=18$ ), $29.0 \pm 2.22$ (score $2, n=171$ ), $26.5 \pm 1.48$ (score $3, n=320), 23.6 \pm 2.09$ (score $4, n=124$ ) and $11.0 \pm 0.78$ (score $5, n=12$ ). The PCV values of FAMACHAC score 1 were significantly different to all the other scores $(P<0.05)$ except for score 2 . The PCV of FAMACHA@ 2, 3 and 4 were not significantly different between themselves. The PCV of FAMACHA@ 5 was the lowest of all the groups.

As expected, the Spearman rank correlation coefficient between the FAMACHAC scores and the PCV was negative $(r=-0.49 ; P<0.001)$. While there was no significant association between the FAMACHAC scores and the FEC $(r=0.06 ; P>0.05)$, the negative association between PCV and FEC was significant $(r=-0.32 ; P<0.001)$. Table 2 includes the sensitivity, specificity, NPV and PPV of FAMACHA@ depending on the scores used to decide an $\mathrm{AH}$ treatment ( 4 and 5 vs. 3, 4 and 5). In the first case, only $20.4 \%$ of the goat population surveyed would have needed $\mathrm{AH}$ 
Table 1

Prevalence of goats shedding nematode eggs per gram (EPG), and statistical description of EPG per age group including the mean ( \pm standard error), range, skewness and proportion of goats eliminating different quantities of EPG.

\begin{tabular}{|c|c|c|c|c|c|c|c|c|c|}
\hline \multirow[t]{2}{*}{ Age groups } & \multirow[t]{2}{*}{$n$} & \multirow[t]{2}{*}{ Prevalence } & \multirow[t]{2}{*}{$\mathrm{EPG}$ mean $\pm \mathrm{SE}$} & \multirow[t]{2}{*}{ Range } & \multirow[t]{2}{*}{ Skewness } & \multicolumn{4}{|c|}{$\begin{array}{l}\text { Proportion (\%) of animals at } \\
\text { different EPG excretions }\end{array}$} \\
\hline & & & & & & A & B & $\mathrm{C}$ & $\mathrm{D}$ \\
\hline 1 (4 months < 1 year) & 485 & $90.7 \%$ & $234.4 \pm 22.61$ & $0-19,200$ & 5.50 & 59.0 & 17.5 & 20.6 & 2.9 \\
\hline $2(>1<2$ years $)$ & 216 & $96.3 \%$ & $398.1 \pm 80.63$ & $0-10,450$ & 4.44 & 47.7 & 23.6 & 27.3 & 1.4 \\
\hline 3 (>2 <3 years) & 70 & $98.5 \%$ & $776.3 \pm 320.27$ & $0-7500$ & 2.46 & 31.4 & 24.3 & 38.6 & 5.7 \\
\hline 4 (>3 < 4 years $)$ & 204 & $91.2 \%$ & $295.1 \pm 96.14$ & 0-9800 & 3.13 & 50.0 & 20.1 & 27.0 & 2.9 \\
\hline 5 (>4 years) & 525 & $92.6 \%$ & $331.1 \pm 66.97$ & $0-10,300$ & 2.93 & 52.6 & 18.9 & 26.1 & 2.5 \\
\hline Total & 1500 & $92.6 \%$ & $315.2 \pm 8.14$ & $0-19,200$ & 4.02 & 52.6 & 19.5 & 25.2 & 2.7 \\
\hline
\end{tabular}

$n=$ number of animals.

$\mathrm{A}=\mathrm{EPG}$ between 0 and 500 .

$\mathrm{B}=\mathrm{EPG}$ between 501 and 1000 .

$\mathrm{C}=\mathrm{EPG}$ between 1001 and 5000 .

$\mathrm{D}=\mathrm{EPG}$ above 5000 .

treatment. Meanwhile, in the second scenario up to $70.4 \%$ of the goat population studied would have needed treatment. Thus, including scores 3, 4, 5 increased the sensitivity and the NPV to detect anemia but it reduces specificity. In the present survey we detected that the large majority of goats scored FAMACHAC 3.

\subsection{Implementing the C-TST combining FAMACHAC, body condition score and FEC}

The 500 EPG threshold for AH treatment resulted in $12.2 \%$ of events receiving AH treatment (Table 3 ), whereas, only $8 \%$ of the events received $\mathrm{AH}$ treatment when 750 EPG were used. Thus, a 500 EPG threshold increased the chances to be treated compared with 750 EPG $(\mathrm{OR}=1.59$, $95 \% \mathrm{CI}=1.36-1.86 ; P<0.05)$. Irrespective of the threshold used, the C-TST scheme allowed to maintain a large proportion of goats in the flock un-treated during the year (34.0-77.6\%). Also, a large proportion of animals received only one AH dose/year (19.1-46\%). Only a minor proportion of goats were treated 2 times and even fewer animals were treated 3 or 4 times.

The total number of events, fecal sampled events and treated events in every month of the survey are presented in Fig. 2A and B. The first graph (Fig. 2A) shows the events accumulated in 2005 and the second graph (Fig. 2B) the events accumulated from 2006 to 2010. There is no clear tendency to have different number of events during the wet season (June-November) or dry season (December-May). However, the contingency tables showed that in 2005 , the chances of receiving an $\mathrm{AH}$ treatment during the wet season were nearly three times higher $(\mathrm{OR}=2.99,95 \% \mathrm{CI}=1.17-1.62 ; P<0.05)$ than in the dry season. However, when the threshold was increased to 750 EPG the opposite occurred and animals had fewer chances to be treated in the wet season compared with dry season (OR=0.87, 95\%CI =0.72-1.04; $P<0.05$ ).

A large number of animals with FAMACHA@ 4, 5 failed to reach the threshold of 500 EPG (83.7\% in 2005) or 750 EPG (57.5\% in 2006-2010) (Table 4). As a consequence, FAMACHA@ 4, 5 showed the lowest sensitivity and PPV in 2005 in spite of the good specificity and NPV. Thus, concordance in the number of animals found positive to 500 EPG between FAMACHAC 4, 5 and the C-TST was close to 0 (poor concordance). The 750 EPG threshold improved the sensitivity and PPV but the concordance remained at medium level.

\section{Discussion}

\subsection{Distribution of nematode fecal egg output in naturally infected goats}

Research on TST schemes for the control of GIN infections in ruminants is centered on the identification of animal features to identify individuals that need an $\mathrm{AH}$ treatment, preferably before the infection affects health or production. The idea of TST is based on epidemiological information showing that only a few animals are affected by GIN and most animals have low

Table 2

Values of sensitivity, specificity, positive predictive value and negative predictive value of the FAMACHA@ method to detect anemic goats ( $n=638$ goats from 20 flocks) when the threshold is set at scores 4 and 5 and when the AH treatment threshold is set at scores 3,4 and 5.

\begin{tabular}{|c|c|c|c|c|}
\hline \multirow[t]{2}{*}{$\mathrm{PCV}^{\mathrm{a}}$ values cut-off points } & \multirow[t]{2}{*}{ Sensitivity (\%) } & \multirow[t]{2}{*}{ Specificity (\%) } & \multicolumn{2}{|c|}{ Predictive values (\%) } \\
\hline & & & Positive & Negative \\
\hline \multicolumn{5}{|c|}{ FAMACHA@ values 4 and 5 considered positive test results } \\
\hline $\mathrm{PCV}<22 \%$ & 60.9 & 84.5 & 30.2 & 95.1 \\
\hline $\mathrm{PCV}<21 \%$ & 60.3 & 83.9 & 27.1 & 95.3 \\
\hline \multicolumn{5}{|c|}{ FAMACHA@ values 3,4 and 5 considered positive test results } \\
\hline $\mathrm{PCV}<22 \%$ & 96.9 & 32.3 & 13.7 & 98.9 \\
\hline $\mathrm{PCV}<21 \%$ & 96.5 & 32.1 & 12.4 & 98.9 \\
\hline
\end{tabular}

Confidence level: $95 \%$.

a PCV, packed cell volume. 
Table 3

Descriptive data of the combined targeted selective treatment (C-TST) scheme in Criollo goats. Treatment decisions are based on a threshold of nematode fecal egg count. Fecal samples are decided according to FAMACHA® and/or body condition score.

\begin{tabular}{|c|c|c|c|c|c|c|c|c|c|c|c|c|c|}
\hline \multirow[t]{2}{*}{ Year $^{\ddagger}$} & \multirow[t]{2}{*}{$N$} & \multirow[t]{2}{*}{ Events } & \multirow[t]{2}{*}{$\begin{array}{l}\text { FAMACHAC } \\
4,5\end{array}$} & \multirow[t]{2}{*}{$\begin{array}{l}\text { C-TST } \\
\text { sampled }\end{array}$} & \multirow[t]{2}{*}{$\begin{array}{l}\text { C-TST not } \\
\text { sampled }\end{array}$} & \multirow[t]{2}{*}{$\begin{array}{l}\text { C-TST not } \\
\text { treated }\end{array}$} & \multirow[t]{2}{*}{$\begin{array}{l}\text { C-TST } \\
\text { treated }\end{array}$} & \multirow[t]{2}{*}{$\begin{array}{l}\text { FAMACHA@ } 4, \\
5 \text { treated goats }\end{array}$} & \multicolumn{5}{|c|}{$\begin{array}{l}\text { Proportion of goats } \\
\text { according to treatment } \\
\text { frequency/year }(\%)\end{array}$} \\
\hline & & & & & & & & & 0 & 1 & 2 & 3 & 4 \\
\hline 2005 & 188 & 2255 & 190 & 674 & 1581 & 1981 & 274 & 31 & 46.3 & 30.0 & 20.0 & 3.8 & 0.0 \\
\hline 2006 & 157 & 1888 & 224 & 327 & 1561 & 1561 & 125 & 74 & 60.0 & 27.5 & 10.0 & 1.3 & 1.3 \\
\hline 2008 & 163 & 1957 & 166 & 392 & 1565 & 1565 & 161 & 87 & 69.1 & 23.5 & 6.6 & 0.8 & 0.0 \\
\hline 2009 & 99 & 1193 & 90 & 303 & 890 & 890 & 99 & 44 & 34.0 & 46.0 & 18.0 & 2.0 & 0.0 \\
\hline 2010 & 83 & 999 & 78 & 229 & 770 & 770 & 98 & 32 & 77.6 & 19.1 & 2.1 & 2.1 & 0.0 \\
\hline Mean & & & & & & & & & 57.4 & 29.2 & 11.3 & 2.0 & 0.3 \\
\hline Total events & & 8292 & 748 & 1925 & 6367 & 7535 & 757 & 268 & & & & & \\
\hline
\end{tabular}

$N=$ average number of goats in the flock per year.

N.A. = data not available.

$\$$ The threshold for treatment during 2005 was 500 eggs per gram of feces (EPG) and the threshold for all the other years was 750 EPG.

(A) Year 2005 (Treatment threshold at 500 eggs per gram (EPG)).

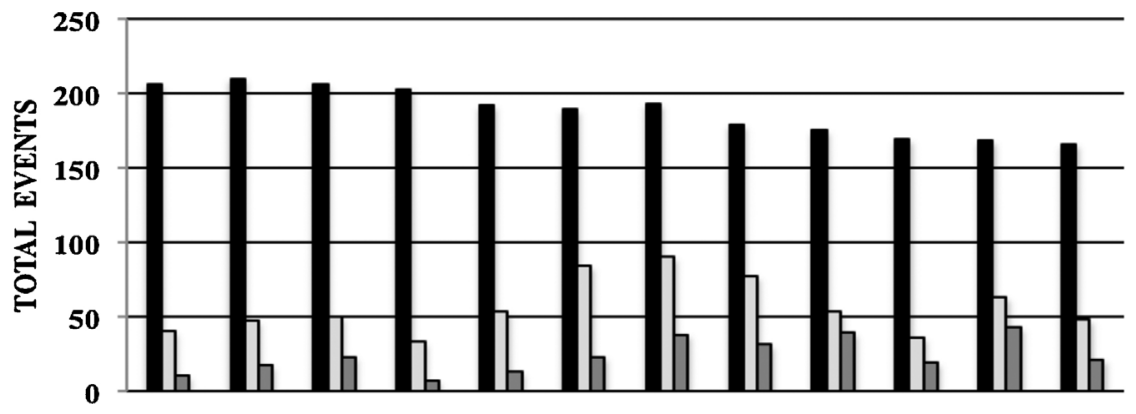

(B) Year 2006-2010 (Treatment threshold at 750 EPG).

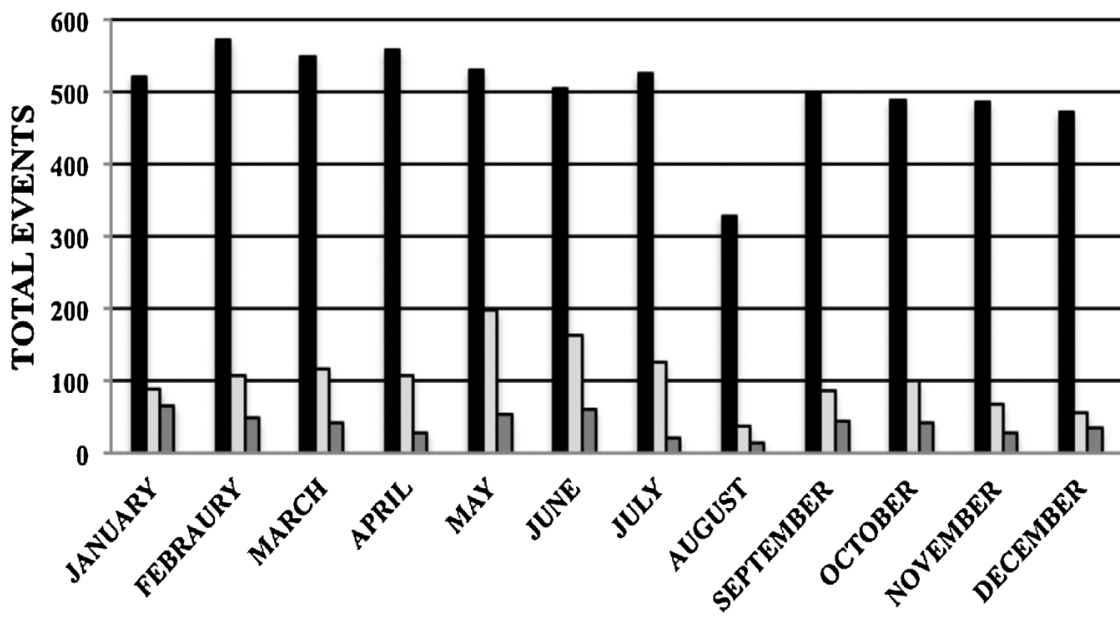

Month

- Total Number of animals in the herd

$\square$ Animals with fecal sample

$\square$ Animals treated

Fig. 2. Cumulative number of events (total, sampled and treated) per month in the years of the combined targeted selective treatment (C-TST) in Criollo goats in Yucatan, Mexico.

Please cite this article in press as: Torres-Acosta, J.F.J., et al., Building a combined targeted selective treatment scheme against gastrointestinal nematodes in tropical goats. Small Ruminant Res. (2014), http://dx.doi.org/10.1016/j.smallrumres.2014.01.009 
Table 4

Values of sensitivity, specificity, positive predictive value and negative predictive value of FAMACHAC scores 4 and 5 to detect goats with nematode eggs (EPG) of at least 500 EPG (year 2005) or 750 EPG (years 2006-2010).

\begin{tabular}{lllll}
\hline PCV values & Sensitivity $\%$ & Specificity \% & Predictive values \% & Concordance \\
\cline { 3 - 5 } & & & Positive & Negative \\
\hline $500 \mathrm{EPG}^{\mathrm{a}}$ & $11.31( \pm 3.75)$ & $91.97( \pm 1.19)$ & $16.32( \pm 5.17)$ & $88.23( \pm 1.39)$ \\
$750 \mathrm{EPG}^{\mathrm{a}}$ & $49.07( \pm 4.46)$ & $94.22( \pm 0.61)$ & $42.47( \pm 4.1)$ & $9.03( \pm 0.04)$ \\
\hline
\end{tabular}

a All the intervals in brackets correspond to the $95 \%$ confidence level.

b Concordance in the number of animals found positive to 500 or 750 EPG when using FAMACHA@ 4-5 or the C-TST using the Youden J (maximum concordance $=1$ and minimum $=0$ ).

infection levels (over-dispersion) (Hoste et al., 2001, 2002). In the present study, the frequency distribution of nematode egg excretions (EPG) was positively skewed in all age groups evaluated and in general (irrespective of age). Thus, egg excretions derived from natural GIN infections in Criollo goats (Haemonchus, Trichostrongylus and Oesophagostmum), showed an aggregated distribution, and were consistent with a negative binomial pattern. In most age groups, the proportion of animals shedding less than 500 EPG was above 50\%, except for age groups 2 and 3. Furthermore, $\sim 70 \%$ shed less than 1000 EPG in most age groups (except for age group 3) and less than 3\% of the individuals had an EPG counts above 5000. Previous epidemiological surveys described over dispersion of FEC in goats under temperate conditions in France (Hoste et al., 2001, 2002) and tropical conditions in Kenya (Keyyu and Kassuku, 1999). The present survey, performed in 103 small-scale goat flocks during the rainy season, confirmed that natural GIN infections in goats of Yucatán show overdispersion. The latter suggested that TST schemes based on EPG were feasible. However, major limiting factors for EPG as indicator are: (a) the lack of threshold EPG value which indicates the need for deworming (Vercruysse and Claerebout, 2001); (b) the technical and economic difficulties for farmers when performing FEC in herds (Bath et al., 2001). Tables for the interpretation of the level of GIN infection based on EPG are available (Hansen and Perry, 1994), but concomitant measurements to improve decision making for deworming are needed.

\subsection{Evaluation of FAMACHA® scores in goats of tropical México (Yucatán)}

Differences in the mean PCV values of respective FAMACHA@ scores, and the significant coefficient of correlation between those, confirmed that this system of classification allowed to distinguish animals in relation to their degree of anemia with a good level of association. Although there was a significant negative association between PCV and FEC data, there was no association between the FAMACHAC scores and the FEC data, even when the study was performed during the wet season, when Haemonchus was abundant. The lack of association between FEC and FAMACHA® scores has been reported in previous goat studies (Scheuerle et al., 2010). The latter suggested that, Haemonchus seem to be one of many health or management problems involved in the clinical evidence of anemia (Ejlertsen et al., 2006). Thus, FAMACHA® and PCV should not be used as the sole criteria to decide an AH treatment. In Yucatán, wet season field studies in which $H$. contortus infections were controlled with copper oxide wire particles failed to show an improvement in PCV of naturally infected browsing goats (Martínez-Ortizde-Montellano et al., 2007). Other field studies with kids showed that the suppressive use of a broad-spectrum persistent drug (moxidectin every 28 days) could not improve PCV unless supplementary feeding was provided either during the wet season (Torres-Acosta et al., 2004) or the dry season (Torres-Acosta et al., 2006). Coprocultures of surveyed flocks showed the typical mixed infection found during the wet season in the study area: Haemonchus, Trichostrongylus and Oesophagostomum (Retama-Flores et al., 2012).

The FAMACHAC sensitivity, specificity, NPV and PPV varied considerably whether animals in score 3 were included amongst the anemic animals needing $\mathrm{AH}$ treatment (scores 4,5 ) or not. The use of FAMACHAC 3, 4, 5 increased sensitivity but reduced specificity. Similar results have been obtained for goats in different countries (Vatta et al., 2001; Kaplan et al., 2004). The inclusion of score 3 amongst treated group reduced the chances to leave an anemic goat without treatment but increased the proportion of false positive results. Also, the proportion of animals needing treatment is increased from $20.4 \%$ (using scores 4 , 5) to $70.5 \%$ (including scores $3,4,5$ ). Thus, if FAMACHA@ 3 , 4,5 were used every month, more than $2 / 3$ of the animals would be treated monthly, which is unacceptable in practical terms. Meanwhile, using FAMACHA@ 4, 5 represents less animals treated per month. The latter, and the fact that a large proportion of surveyed goats scored 3, suggested that the use of FAMACHA® in Yucatán must rely on scores 4 and 5 as the threshold for $\mathrm{AH}$ treatment. The latter differs to previous recommendations when FAMACHA@ is used as the sole criteria for AH treatment (Vatta et al., 2001; Kaplan et al., 2004; Ejlertsen et al., 2006). Finally, the lack of association between EPG and FAMACHAC scores indicated that another marker must be included in the search for animals needing AH treatment as suggested by Van Wyk and Bath (2002).

The sensitivities observed in the present study for FAMACHAC scores 4,5 and 3, 4, 5 where higher than those recorded in previous goat studies in South Africa (Vatta et al., 2001), United States (Kaplan et al., 2004), Guadeloupe (Mahieu et al., 2007) and Switzerland (Scheuerle et al., 2010). It is possible that the sensitivity in the present study was better because the anemia cut-off points employed were obtained from local data of browsing Criollo goats (Torres-Acosta, 1999). 
4.3. Implementing the C-TST combining FAMACHA®, body condition score and FEC

In the proposed C-TST scheme, FAMACHAC is used to identify anemic animals with great specificity (scores 4,5 ), which may include animals with high $H$. contortus infections. The low BCS could identify those animals affected by non-hematophagous GIN parasites. Both indicators were used to identify animals at risk. Then, the FEC was used to confirm that a given goat required AH treatment. However, the C-TST scheme still required to develop a crucial indicator: the FEC threshold for the treatment decision. The epidemiological information presented in Table 1 suggested that nearly $50 \%$ of the animals would have more than 500 EPG at a given time. Thus, such threshold would represent a large proportion of animals receiving treatment. In spite of that, the 500 EPG threshold was decided in order to reduce the chances of losses due to GIN (welfare requirements). The lack of any clinical problem in the goats during 2005 increased the confidence to raise the treatment threshold to 750 EPG for the following year. The latter helped to reduce the chances of being treated 1.59 times $(\mathrm{OR}=1.59,95 \% \mathrm{CI}=1.36-1.86 ; P<0.05)$. Thus, the 750 EPG threshold was used from years 2006-2010 without any negative effect on welfare, health and production of untreated animals. A recent TST trial by Morales et al. (2008) used a threshold of 800 EPG in sheep and confirmed the absence of any negative effect for the untreated animals.

The C-TST scheme presented here produced several advantages for the protection of refugia. Firstly, the proportion of animals left without treatment was $57.4 \%$ (average of all surveyed years) with no apparent negative consequences for the animals. This proportion includes all those goats that were not anemic (FAMACHA@ 1, 2,3) or showed good BCS ( 2.5 or higher), which were not sampled, and also all the animals that were sampled but had fewer than 750 EPG. Secondly, approximately one-third of the goats were treated once a year only. Besides, treatments are applied to the different animals in different months. Thus, AH treatments are spread amongst individuals throughout the year (Fig. 2A and B). As a consequence, the chance of receiving an $\mathrm{AH}$ treatment during the wet season was similar during the dry season $(\mathrm{OR}=0.87,95 \% \mathrm{CI}=0.72-1.04 ; P<0.05)$ when the threshold of AH treatment was 750 EPG. Fewer individuals treated per month may reduce the selection pressure for resistance compared with mass AH treatment at a given time point, especially during the dry season when infective larvae in the soil and vegetation become desiccated. Previous trials with goats did show a tendency to treat more animals during the wet season using FAMACHAC scores 4 , 5 (Vatta et al., 2002a). In the present study the FEC helped to avoid unnecessary AH treatments during the wet season. Thirdly, less than $15 \%$ of the goats are treated on repeated occasions in a year ( 2 or more). These few animals might be included in a program to improve their diet aiming at enhancing their resilience in the long term. The small proportion of animals with 3 or more treatments $(2.3 \%)$ can be supervised in order to decide whether animals are showing a welfare problem or a concomitant disease. Such information may be used to assist culling decisions.
The elements included in the C-TST improved the low sensitivity of FAMACHA@ 4, 5 as criteria to detect animals with 500 EPG or 750 EPG (see Table 4). Such low sensitivity of scores 4,5 and the low concordance value can be related to the fact that, at least half of the events with 750 EPG were detected from animals with high FAMACHAC scores $(1,2,3)$ but showing poor BCS (less than 2.5). Besides, many animals with scores 4, 5 had FEC lower than 750 EPG. Similarly, Scheuerle et al. (2010) reported that only in $43.5 \%$ of all their cases, the decision for a treatment according to FAMACHA@ was in agreement with recommendations for treatment of goats with FEC higher than 300 EPG and in 36.6\% with FEC higher than 600 EPG. The latter justify the need to use FAMACHAC and BCS only as indicators to identify animals at risk of severe GIN infection.

A large number of sampled events resulted from animals showing low BCS but not needing AH treatment (Table 3 and Fig. 2A, B). Only half of the events treated with AH were detected from animals with poor BCS. It is evident that, under the conditions of the present study, the BCS could not be used as the sole indicator of parasitic problems as it is strongly associated with the balance between nutrition, production level and many disease conditions (Van Wyk and Bath, 2002) and parasitic infections seem to be a minor factor influencing BCS (Honhold et al., 1993; Vatta et al., 2002b; Burke et al., 2007). It is desirable to find an adequate cut-off point for the BCS that allow reducing the number of animals sampled per month. Recent studies with sheep in commercial farms of Yucatán showed that animals with BCS above 3 seldom need AH treatment, in spite of having poor FAMACHA@ scores (Soto-Barrientos, 2012). The latter is consistent with the work performed with Creole goats in Guadeloupe (Mahieu et al., 2007). Further in-depth data analyses might help to identify the best cut-off point for the BCS in this C-TST scheme for goats.

An important deterrent for the use of the C-TST is the need for the FEC. It is evident that C-TST will require the participation of qualified technical staff trained to correctly perform the McMaster technique. Although the need for FEC can be considered as a cost difficult to accept by most farmers (Bath et al., 2001; Van Wyk et al., 2006), it might be included as part of the assistance package. By doing so, rather than an objection, the FEC may become the key to start working with farmers groups for many new professionals. Thus, the C-TST scheme might become a means toward strengthening the link between farmers and professionals leading to the improvement of animal production and welfare while improving the economy of farmers and providing new jobs for professionals.

\section{Conclusion}

The C-TST scheme for the control of natural GIN infections reduced the frequency of $A H$ treatments in goats. The system is based on the natural over-dispersion of natural GIN infections of goats from Yucatán, México. The FAMACHAC and BCS help to identify animals at risk of severe GIN infections, while the FEC avoid unnecessary $\mathrm{AH}$ treatments. The C-TST reduce the number of animals treated per year in the herd, leaving a large proportion 
of goats without AH treatment. This strategy could help to maintain refugia of susceptible worms in the farm by reducing the number of animals treated and distributing treatments throughout the year. The application of this scheme in other goat or sheep farms in other areas of the world needs to be evaluated before extensive use is advised.

\section{Conflict of interest statement}

None of the authors of this paper has a financial or personal relationship with other people or organizations that could inappropriately influence or bias the content of the paper.

\section{Acknowledgments}

Authors acknowledge the technical help of Edgar España-España, Cristina Vera-Ayala, Juan Uitz-Rodríguez, Jesús Heredia-López and Isidro Gutiérrez-Segura. We thank goat farmers of Yucatán, México, who allowed us to perform the field surveys and the workers at the FMVZ-UADY goat farm for using and recording the TST scheme results monthly for 7 years. Dr. Armando Nari is thanked for providing us the first FAMACHA® chart and Dr. Jan Van-Wyk for the FAMACHA@ training course in México. ECOS-Nord, France/CONACYT-ANUIES, Mexico (Project No. M03-A03) provided part of the funding for the farmers' survey study.

\section{References}

Bath, G.F., Hansen, J.W., Krecek, R.C., van Wyk, J.A., Vatta, A.F., 2001. Sustainable approaches for managing haemonchosis in sheep and goats. Final Report of Food and Agriculture Organization (FAO) Technical Co-operation Project No. TCP/SAF/8821(A). Rome, Italy.

Bowman, D.D., Lynn, R.C., 1999. Georgis' Parasitology for Veterinarians, 7th ed. W.B. Saunders, Philadelphia, USA.

Burke, J.M., Kaplan, R.M., Miller, J.E., Terrill, T.H., Getz, W.R., Mobini, S., Valencia, E., Williams, M.J., Williamson, L.H., Vatta, A.F., 2007. Accuracy of the FAMACHA system for on-farm use by sheep and goat producers in the southeastern United States. Vet. Parasitol. 147, 89-95.

Cody, R.P., Smith, J.K., 1991. Applied Statistics and the SAS Programming Language, 3rd ed. Elsevier Science Publishing Company, New York, North-Holland.

Ejlertsen, M., Githigia, S.M., Otieno, R.O., Thamsborg, S.M., 2006. Accuracy of an anaemia scoring chart applied on goats in sub-humid Kenya and its potential for control of Haemonchus contortus infections. Vet. Parasitol. 141, 291-301.

Flores-Guido, J.S., Espejel-Carvajal, I., 1994. Tipos de vegetación de la península de Yucatán. Etnoflora yucatanense. Universidad Autónoma de Yucatán, Mérida, Yucatán, México.

Hansen, J., Perry, B., 1994. The Epidemiology, Diagnosis and Control of Helminth Parasites of Ruminants. FAO-ILRAD, Nairobi, Kenya, pp. $17-24$.

Honhold, N., Petit, H., Halliwell, R.W., 1989. Condition scoring scheme for Small East African goats in Zimbabwe. Trop. Anim. Health Prod. 21, 121-127.

Honhold, N., Torres-Acosta, J.F., Dominguez-Alpizar, J.L., 1993. The relationship of gastrointestinal helminthiasis and body condition score of goats in state of Yucatan, Mexico. IFS/IAEA/FAO Workshop on "Animal Disease Diagnostics in Latinamerica" San José, Costa Rica. Octubre-noviembre 1993. Universidad Nacional Heredia, Costa Rica.

Hoste, H., Le Frileux, Y., Pommaret, A., 2001. Distribution and repeatability of faecal egg counts and blood parameters in dairy goats naturally infected with gastrointestinal nematodes. Res. Vet. Sci. 70 $50-57$.
Hoste, H., Le Frileux, Y., Goudeau, C., Chartier, C., Pors, I., Broqua, C., Bergaud, J.P., 2002. Distribution and repeatability of nematode faecal egg count in dairy goats: a farm survey and implications for worm control. Res. Vet. Sci. 72, 211-215.

Kaplan, R.M., Burke, J.M., Terrill, T.H., Miller, J.E., Getz, W.R., Mobini, S., Valencia, E., Williams, M.J., Williamson, L.H., Larsen, M., Vatta, A.F., 2004. Validation of the FAMACHAC eye color chart for detecting clinical anemia in sheep and goats on farms in the southern United States. Vet. Parasitol. 123, 105-120.

Kenyon, F., Greer, A.W., Coles, G.C., Cringoli, G., Papadopoulos, E., Cabaret, J., Berrag, B., Varady, M., Van Wyk, J.A., Thomas, E., Vercruysse, J., Jackson, F., 2009. The role of targeted selective treatments in the development of refugia-based approaches to the control of gastrointestinal nematodes of small ruminants. Vet. Parasitol. 164, 3-11.

Keyyu, J.D., Kassuku, A.A., 1999. The Distribution of Nematode Egg Counts in Grazing Goats and its Implications for Helminths Control. Department of Veterinary Microbiology and Parasitology, Sokoine University of Agriculture, Morogoro, Tanzania.

MAFF, 1986. Helminthology. In: F.A.F. Ministry of Agriculture (Ed.), Manual of Veterinary Parasitological Laboratory Techniques. Her Majesty's Stationary Office, London, pp. 1-65.

Mahieu, M., Arquet, R., Kandassamy, T., Mandonnet, N., Hoste, H., 2007. Evaluation of targeted drenching using Famacha $\odot$ method in Creole goat: reduction of anthelmintic use, and effects on kid production and pasture contamination. Vet. Parasitol. 146, $135-147$

Martínez-Ortiz-de-Montellano, C., Vargas-Magaña, J.J., Aguilar-Caballero, A.J., Sandoval-Castro, C.A., Cob-Galera, L., May-Martínez, M., MirandaSoberanis, L., Hoste, H., Torres-Acosta, J.F.J., 2007. Combining the effects of supplementary feeding and copper oxide needles improves the control of gastrointestinal nematodes in browsing goats. Vet. Parasitol. 146, 66-76.

Morales, G., Sandoval, E., Pino, L.A., Rondón, Z., 2008. Evaluación de dos criterios de utilidad en un programa de control de la infección por nematodos gastrointestinales en ovinos mediante tratamiento antihelmíntico selectivo. Zootecnia Trop. 26, $141-150$.

Retama-Flores, C., Torres-Acosta, J.F.J., Sandoval-Castro, C.A., AguilarCaballero, A.J., Cámara-Sarmiento, R., Canul-Ku, H.L., 2012. Maize supplementation of Pelibuey sheep in a silvopastoral system: fodder selection, nutrient intake and resilience against gastrointestinal nematodes. Animal 6, 145-153.

Rodríguez-Vivas, R.I., Cob-Galera, L.A., 2005. Técnicas Diagnósticas en Parasitología Veterinaria, 2da Edición. Universidad Autónoma de Yucatán, México, p. 306.

Scheuerle, M., Mahling, M., Muntwyler, J., Pfister, K., 2010. The accuracy of the FAMACHAC-method in detecting anaemia and haemonchosis in goat flocks in Switzerland under field conditions. Vet. Parasitol. 170, 71-77.

Soto-Barrientos, N., 2012. Desparasitación Selectiva en ranchos comerciales de ovinos de Yucatán, Tesis. Maestría en Producción Ovina Tropical. FMVZ, Universidad Autónoma de Yucatán, Mérida, México.

Torres-Acosta, J.F.J., 1999. Supplementary feeding and the control of gastro intestinal nematodes of goats in Yucatan Mexico. Royal Veterinary College, University of London, London, UK (Ph.D. thesis).

Torres-Acosta, J.F.J., Jacobs, D.E., Aguilar-Caballero, A., Sandoval-Castro, C., May-Martínez, M., Cob-Galera, L.A., 2004. The effect of supplementary feeding on the resilience and resistance of browsing Criollo kids against natural gastrointestinal nematode infections during the rainy season in tropical Mexico. Vet. Parasitol. 124, $217-238$

Torres-Acosta, J.F.J., Jacobs, D.E., Aguilar-Caballero, A., Sandoval-Castro, C., Cob-Galera, L., May-Martinez, M., 2006. Improving resilience against natural gastrointestinal nematode infections in browsing kids during the dry season in tropical Mexico. Vet. Parasitol. 135, 163-173.

Thrusfield, M., Ortega, C., De-Blas, I., Noordhuizen, J.P., Frankena, K., 2001. WIN EPISCOPE 2.0: improved epidemiological software for veterinary medicine. Vet. Rec. 148, 567-572.

Van Wyk, J.A., Bath, G.F., 2002. The FAMACHAC system for managing haemonchosis in sheep and goats by clinically identifying individual animals for treatment. Vet. Res. 33, 509-529.

Van Wyk, J.A., Hoste, H., Kaplan, R.M., Besier, R.B., 2006. Targeted selective treatment for worm management-how do we sell rational programs to farmers? Vet. Parasitol. 139, 336-346.

Vatta, A.F., Letty, B.A., van der Linde, M.J., van Wijk, E.F., Hansen, J.W., Krecek, R.C., 2001. Testing for clinical anaemia caused by Haemonchus 
spp. in goats farmed under resource-poor conditions in South Africa using an eye colour chart developed for sheep. Vet. Parasitol. 99, 1-14.

Vatta, A.F., Krecek, R.C., Letty, B.A., van der Linde, M.J., Grimbeek, R.J., de Villiers, J.F., Motswatswe, P.W., Molebiemang, G.S., Boshoff, H.M., Hansen, J.W., 2002a. Incidence of Haemonchus spp. and effect on haematocrit and eye colour in goats farmed under resource-poor conditions in South Africa. Vet. Parasitol. 103, 119-131.
Vatta, A.F., Krecek, R.C., Letty, B.A., van der Linde, M.J., Motswatswe, P.W., Hansen, J.W., 2002b. Effect of nematode burden as assessed by means of faecal egg counts on body condition in goats farmed under resourcepoor conditions in South Africa. Vet. Parasitol. 108, 247-254.

Vercruysse, J., Claerebout, E., 2001. Treatment vs non-treatment of helminth infections in cattle: defining the threshold. Vet. Parasitol. $98,195-214$. 